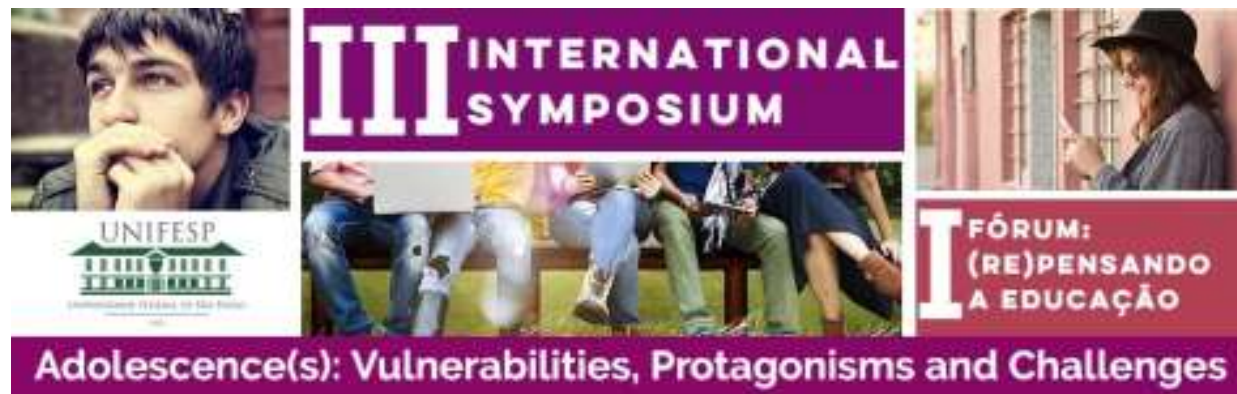

THE IMPORTANCE OF PRACTICAL LESSONS AS TEACHING TOOL: AN EXPERIENCE WITH ELEMENTARY SCHOOL STUDENTS I DO NEIPAULISTINHA

\title{
A IMPORTÃNCIA DE AULAS PRÁTICAS COMO FERRAMENTA DE ENSINO: UMA EXPERIÊNCIA COM ALUNOS DO ENSINO FUNDAMENTAL I DO NEI-PAULISTINHA
}

Maristela C. B. Freire루 Cecília S. S. de Freitas ${ }^{2}$; Gilvanice Lima ${ }^{3}$; Paula de A. Silvério ${ }^{4}$; Patrícia A. Bersanetti ${ }^{5}$

1. Coordenadora Pedagógica do NEI - Paulistinha maristelacb@uol.com.br

2. Professora do Ensino Fundamental do NEI - Paulistinha ceciliassf@yahoo.com.br

3. Professora do Ensino Fundamental do NEI - Paulistinha gilenf@hotmail.com

4. Aluna de graduação em Tecnologia em Informática em Saúde da Escola Paulista de Medicina/Unifesp. paulaaraujosilverio@live.com

5. Professora do Departamento de Bioquímica da Escola Paulista de Medicina/Unifesp. bersanetti@unifesp.br

* Projeto de Extensão

\section{Como citar:}

FREIRE, Maristela C. B. et al. The importance of practical lessons as teaching tool: an experience with elementary school students i do nei-paulistinha. In: INTERNATIONAL SYMPOSIUM ADOLESCENCE(S) \& FÓRUM (RE)PENSANDO A EDUCAÇÃO, 3, 2017, São Paulo. Anais... São Paulo: Unifesp, 2017. p. $37-38$. DOI: http://dx.doi.org/10.22388/2525-5894.2017.017

Introdução: Nas últimas décadas dados estatísticos comprovam um aumento significativo das crianças e adolescentes matriculados na Educação Básica, o que justifica a necessidade de discussões acerca de políticas públicas voltadas para essa etapa e sobre o tipo de participação que se espera dos sujeitos na sociedade contemporânea. Nessa perspectiva, os sujeitos da Educação Básica, devem ter garantia do acesso ao conhecimento produzido pela humanidade que na escola é veiculado pelos conteúdos curriculares.

Objetivos: Analisar a importância de atividades práticas para alunos do Ensino Fundamental.

Métodos: A proposta nasceu da parceria do Projeto de extensão "Brincando com Ciências: 
experimentos para alunos do Ensino Fundamental I", coordenado pela Profa. Dra. Patrícia A. Bersanetti, e desenvolvido com o NEI-Paulistinha. O Projeto iniciou-se em 2016 e continua a ser desenvolvido ao longo de 2017, com a participação dos alunos do $4^{\circ}$ e $5^{\circ}$ anos do Ensino Fundamental. Inicialmente, os alunos recebem informações através de palestras e vídeos e, na sequência, participam de práticas realizadas no NEI-Paulistinha e em laboratórios didáticos da Unifesp. No período os alunos participaram ainda de visita monitorada ao Museu de Geociências da USP. Os temas abordados foram relacionados ao conteúdo curricular e aprofundados conforme interesse dos alunos. No final de cada ciclo os alunos eram incentivados a registrar suas experiências.

Resultados: Através das atividades teóricas e práticas foi possível estabelecer relações entre os conteúdos curriculares com suas aplicações para a vida cotidiana, o que possibilitou uma maior compreensão acerca desses conteúdos e um aumento do interesse por parte dos alunos sobre essas temáticas. Esses dados podem ser evidenciados nos registros das atividades através de anotações e material fotográfico.

Conclusões: O contato do aluno com vivências práticas despertam o interesse científico e a motivação para o aprendizado do conteúdo curricular abordado.

Palavras-Chave: Ensino. Educação. Ensino Fundamental I. 